\title{
The Application of Probability Theory in the Percentage of People Having Myopia Caused by Inheritance
}

\begin{abstract}
Kun Liu
San Mateo High School

dennis30313233@gmail.com

ABSTRACT

Myopia is one of the most common diseases in today's society. More and more people indeed wear glasses when they are young, even some kids wear glasses in kindergarten. The topic of this paper is to investigate one of the main factors, inheritance, that cause myopia. This paper tries to use the method of probability theory to provide a clear image of myopia situation, understand the effect of inheritance, and form their cognition on this common disease, so as to realize the reality of myopia in our lives. The data in this paper comes from official statistic research. The result turns out that today's severe myopia situation is not solely caused by inheritance. Inheritance can only be considered as one factor that causes myopia so popular in our society. To slow down the process of the spread of myopia in society, there are a lot of other factors that need to control.
\end{abstract}

Keywords: myopia, probability theory, Markov Chain, prediction rate.

\section{INTRODUCTION}

According to an experiment of heritability, the results suggested that the prevalence of myopia increased statistically significantly with the number of myopic parents; the associated development risk rates are $7.6 \%$ for no myopic parents, $14.9 \%$ for one myopic parent, and $43.6 \%$ for two myopic parents. It shows the different percentages that people getting myopia problems based on their different situations[1]. Today, nearly 40 percent of the U.S. population has myopia, or nearsightedness, and it's only expected to grow. Based on the data and the seemingly unstoppable increasing tendency, it is important and worthy for people to investigate further in this area and provide some effective advice[2]. Studies toward the molecular genetics of myopia are well established and have pointed out the critical role of genetic factors. Scientists and other researchers in the area of myopia continue to work on the factors causing myopia and evaluate the exact percentage seriousness of these factors causing myopia. The blank in this research area is the prediction of myopia problem in the future and the level of seriousness of inheritance on myopia and the effective method that controls the myopia problem or even slows down the process of myopia expansion. This paper tries to further indicate the problem of inheritance and predict the myopia problem condition in the future by using the Markov chain. The purpose of this research is to predict the myopia situation in the future and to provide some advice that effectively slows down the expansion process of the myopia problem in our society. Besides, this paper makes the complex concepts to be understood easily and reveals the importance of understanding myopia in our society.

\section{ANALYSIS: THE PREDICTION OF PEOPLE WITH MYOPIA IN THE FUTURE}

\section{1. number of births in the United States}

Based on the official research, approximately 3.75 million babies were born in 2019[3]. To put it simply, assuming that each couple has one baby, which means there are 3.75 million couples in our experiment. That is to say, there are 7.5 million people in our sample and gender is not important in this experiment. Nearly 40 percent of the U.S. population has myopia. It turns out that there are 3.0 million people with myopia in our sample, and the other 4.5 million people have no myopia. $7,500,000 \times 40 \%=3,000,000$. 


\section{2. mate probability in the sample}

In the sample, people with myopia have two mate options: mate with the person who also has myopia and mate with the person who has no myopia. Similarly, people with no myopia in our sample also have two options: mate with the person who also has no myopia and mate with the person who has myopia. According to the research, the importance of high status and likable personality was not influenced by sightedness[4]. Since there is no clear preference mate in the United States society between people who have myopia and have not, $50 \%$ of people with myopia mate to people also with myopia, and another $50 \%$ of people with myopia mate to people with no myopia. That is to say, 3 million people with myopia in our experiment can be divided into 1.5 million males with myopia and 1.5 million females with myopia. It can be inferred that $50 \%$ of 1.5 million males mate to people with myopia in our experiment, which takes out $1 / 2$ of 1.5 million females with myopia. In other words, 0.75 million males with myopia mate to 0.75 females also with myopia. In other words, as shown in table 1 there are 0.75 million couples that both have myopia. Another $1 / 2$ males and females with myopia mate to person have no myopia in this sample. As a result, in 1.5 million couples that one person has myopia. Next, in our experiment, there are 3 million people with no myopia left. As a result, there are 1.5 million couples that both have no myopia. The specific data is shown below.

Table 1. Types of couples in this experiment

\begin{tabular}{|l|l|}
\hline Couples & Total number \\
\hline $\begin{array}{l}\text { Couples that both have } \\
\text { myopia }\end{array}$ & 0.75 million \\
\hline $\begin{array}{l}\text { Couples that one of them } \\
\text { has myopia }\end{array}$ & 1.5 million \\
\hline $\begin{array}{l}\text { Couples that both have } \\
\text { no myopia }\end{array}$ & 1.5 million \\
\hline
\end{tabular}

\subsection{The Markov chain using in this experiment}

In 1906, Russian mathematician aamarisov proposed the Markov chain, which is a discrete sequence stochastic process with Markov property in mathematics. In this process, given the current information, the past (that is, the historical state before the current) is irrelevant to the prediction of the future (that is, the future state after the current event)[5].

In the experiment, there are two types of current events: people with myopia and people without myopia.

People have no myopia: Based on the sample data, there are 1.5 million couples that both have no myopia. According to the research, the associated development risk rates of having myopia by inheritance are $7.6 \%$ for no myopic parents. Assuming the current state is S1, people have no myopia, the probability that the next step also is S1 is approximately 0.924 . And the probability that the next step is S2, for people with myopia, is 0.076 . There is another group of people, couples that one of both has myopia (one of both has no myopia), also have no myopia in our experiment. However, in this sample data, the probability that the next step is $\mathrm{S} 1$, people have no myopia, is approximately 0.85 . And the probability that the next step is S2, people have myopia, is 0.15 .

People have myopia: Based on the sample data, there are 0.75 million couples that both have myopia. According to the research, the associated development risk rates of having myopia by inheritance are $43.6 \%$ for two myopic parents. Assuming current state S1, people have no myopia, the probability of next step is also $\mathrm{S} 1$ is approximately 0.564 . And the probability that the next step is $\mathbf{S} 2$, people have myopia, is 0.436 . Similar to the people with myopia sample, there are people who have myopia in the couples that one of both has myopia. And the probability that the next step is $\mathrm{S} 1$, people have no myopia, is approximately 0.85 . And the probability that the next step is S2, people have myopia, is 0.15 .

As a result, there are approximately 0.114 million new babies with myopia and 1.386 million new babies with no myopia reproduced by the couples that both have no myopia group. And couples that one of both has myopia will reproduce approximately 0.225 million new babies with myopia and 1.275 million new babies with no myopia. The last group, couples that both have myopia, will reproduce approximately 0.327 million new babies with myopia and 0.423 million new babies with no myopia. In total, there are 0.666 million new babies with myopia and 3.084 million new babies have no myopia. However, 0.666 million is only 17.76 percent of the total, which seemingly contradicts the fact that nearly $40 \%$ of people have myopia in the United States society.

\section{4. another mate probability in the sample}

In the experiment above, the result contradicts the fact. In this experiment, the sample of couples is changed in order to get close to the fact that 40 percent of people have myopia in the United States society. Researchers assume people have myopia only mate with people who also have myopia. And people who have no myopia mate with people who also have no myopia.

Table 2. Types of couples in this experiment

\begin{tabular}{|l|l|}
\hline Couples & Total number \\
\hline $\begin{array}{l}\text { Couples that both have } \\
\text { myopia }\end{array}$ & 1.5 million \\
\hline $\begin{array}{l}\text { Couples that both have } \\
\text { no myopia }\end{array}$ & 2.25 million \\
\hline
\end{tabular}


In the experiment, there are two types of current events: people with myopia and people without myopia.

People have no myopia: Based on the sample data, there are 2.25 million couples that both have no myopia. The associated development risk rates of having myopia by inheritance are $7.6 \%$ for no myopic parents. Assuming the current state is $\mathrm{S} 1$, people have no myopia, the probability that the next step also is S1 is approximately 0.924 . And the probability that the next step is $\mathrm{S} 2$, for people with myopia, is 0.076 .

People have myopia: Based on the sample data, there are 1.5 million couples that both have myopia. The associated development risk rates of having myopia by inheritance are $43.6 \%$ for two myopic parents. Assuming current state $\mathrm{S} 1$, people have no myopia, the probability of next step is also S1 is approximately 0.564 . And the probability that the next step is $\mathrm{S} 2$, people have myopia, is 0.436 .

As a result, there are approximately 0.171 million new babies with myopia and 2.079 million new babies with no myopia reproduced by the couples that both have no myopia group. And couples that both have myopia, will reproduce approximately 0.654 million new babies with myopia and 0.846 million new babies with no myopia. In total, there are 0.825 million new babies with myopia and 2.925 million new babies have no myopia. However, 0.825 million is only 22 percent of the total, which also seemingly contradicts the fact that nearly $40 \%$ of people have myopia in the United States society.

Table 3. The percent of new babies with myopia in these two experiments

\begin{tabular}{|l|l|l|}
\hline Experiment type & Result & Fact \\
\hline $\begin{array}{l}\text { Experiment 1(half } \\
\text { of people with } \\
\text { myopia mate with } \\
\text { people who also } \\
\text { with myopia, and } \\
\text { another half mate } \\
\text { with people have } \\
\text { no myopia) }\end{array}$ & $40 \%$ of total \\
\hline $\begin{array}{l}\text { Experiment 2 } \\
\text { (people have } \\
\text { myopia only mate } \\
\text { with people who } \\
\text { also have myopia, } \\
\text { and people have } \\
\text { no myopia mate }\end{array}$ & $22 \%$ of total & $40 \%$ of total \\
\hline
\end{tabular}

\begin{tabular}{|l|l|l|}
\hline with people who & & \\
also have no & & \\
myopia) & & \\
\hline
\end{tabular}

\section{5. prediction on the percentage of people having myopia caused by inheritance in next decade}

Based on the data, there were 3.75 million new babies born in 2019. The percentage of babies who have myopia is below 20 percent. Even though these new babies cannot contribute to the reproduction in coming years, it could be predicted that the percentage of people having myopia in the United States will only decrease. If only considered inheritance, myopia problem will be less and less severe in the future.

\section{DISCUSSION}

Based on the result from the inheritance experiment, inheritance cannot solely cause myopia that nearly $40 \%$ of Americans have myopia in society, which infers that there must be some other factors that lead to the myopia problem in people's lives. According to the research, the economic and social burdens, associated with ocular complications may lead to visual impairment[6]. Indeed, in today's society, people face much more challenges than in past decades. Unemployment, loan of money, severe competitive competition in jobs, and take care of family, all could contribute to myopia. The prevalence of myopia among university students was $86.8 \%$ [7]. This astonishing data shows that the people are loaded with heavy burdens caused by the competition. In today's society, attending to college and get a degree is the most simple and popular path to succeed. With millions of people attending college every year, the competition between people could only be more severe and harsh. With this pressure, people are more likely to get myopia. Besides, it is much harder to make big money today than in decades before. Indeed, the improvement of society can only make the competition more competitive because the easier path has already been taken away by people in the past. In addition, the environmental factors implicated in myopia include light exposure, lack of physical activity, diet, pollution, and urbanization[8]. That is to say, nearly everything in people's life affects our eyes. For example, as technology improves, the cell phone takes the most of the time of people in their daily life. However, cell phones could affect human eyes greatly. The blue light, emitted from most cellphones and computers promotes the growth of "poisonous molecules" in our eyes, which leads to macular degeneration, stated scientists. Blue light harms human vision by damaging the eye's retina, professor and study co-author Ajith Karunarathne said about the study, which was published in the journal Scientific Reports[9]. In today's society, it 
is common to see a child who carries a smartphone in his hand in the street. Admittedly, the technology improvement in our society provides a lot of advantages to our lives, but the potential problem of myopia caused by this high-tech cannot be overlooked. Consequently, slowing down the problem of myopia is much harder than we thought. And it needs people to take a huge effort in the coming years.

\section{CONCLUSION}

Inheritance does cause myopia in our society today but inheritance is not that severe. If only consider the factor of inheritance, the percentage of people have myopia in our society will decrease based on our research outcome: less than 20 percent of new babies have myopia problem which caused by inheritance. Inheritance is not the main factor that causes myopia is such a common disease in today's society. The purpose of clearing the fog and seeing the percentage of people getting myopia by inheritance is to the analysis part of this severe situation of myopia. Only when we fully understand the factors that contribute to myopia, have a glimpse of the essence of myopia, can we effectively control and slow down the process of surplus in getting myopia.

\section{ACKNOWLEDGMENTS}

I would like to express my deep and sincere gratitude to my paper advisor, Pierre Clare, professor in the Mathematics department at College of William and Mary, for giving me the direction and process of my paper and providing knowledge and background of probabilities in mathematics. He has taught me the methodology to carry out my paper and to present the paper works as clearly as possible. I am extremely grateful for what he has offered me.

\section{REFERENCES}

[1] Wojciechowski R, Congdon N, Bowie H, Munoz B, Gilbert D, West SK. Heritability of refractive error and familial aggregation of myopia in an elderly American population.Invest Ophthalmol Vis Sci.2005;46:1588-92

[2] The World Is Rapidly Becoming More Nearsighted Alexandra Ossola | Published Feb 18- blindness eyes glaucoma Health myopia- Blindness- EyesGlaucoma- Health- Myopia https://www.popsci.com/nearly-5-billion-peoplewill-be-nearsighted-by-2050/

[3] Births in the U.S. 2019 Published by Statista Research Department-May 5 https://www.statista.com/statistics/195908/numberof-births-in-the-united-states-since-1990/
[4] Meike Scheller 2021 Apr 13 "The role of vision in the emergence of mate preferences" doi: 10.1007/s10508-020-01901-w.

[5] He xuansen. (2009) stochastic process, people's post and Telecommunications Press, Beijing

[6] E. Dolgin, "The myopia boom," Nature, vol. 519, no. 7543, pp. 276-278, 2015.

[7] The Prevalence Of Myopia and the Factors Associated with It Among University Students in Nanjing: A Cross-sectional Study.Luoming HuangHiromi Kawasaki-Yiqun Liu-Zhongliang Wang https://www.ncbi.nlm.nih.gov/pmc/articles/PMC64 $17623 /$

[8] Myopia: Risk Factors, Disease Mechanisms, Diagnostic Modalities, and Therapeutic Options Malgorzata Mrugacz-Marzena Gajecka-Ewa Mrukwa-Kominek-Katarzyna Witkowska https://www.hindawi.com/journals/joph/2018/7942 $379 /$

[9] Your Phone Is Blinding You, Scientists Warn Hannah Sparks - https://nypost.com/2018/08/13/yourphone-is-blinding-you-scientists-warn/ 